\title{
Evaluation of the Characteristics of Asthma in Severe and Extremely Severe COPD
}

This article was published in the following Dove Press journal:

International Journal of Chronic Obstructive Pulmonary Disease

\section{Feng-jia Chen (1)* \\ Geng-peng Lin* \\ Xin-yan Huang (ID \\ Yang-li Liu \\ Zhi-min Zeng \\ Yu-biao Guo}

Department of Pulmonary and Critical Care Medicine, The First Affiliated Hospital, Sun Yat-Sen University,

Guangzhou, People's Republic of China

*These authors contributed equally to this work
Correspondence: Yu-biao Guo Department of Pulmonary and Critical Care Medicine, The First Affiliated Hospital of Sun Yat-Sen University, Institute of Respiratory Diseases of Sun Yat-Sen University, No. 58 Zhongshan 2nd Road, Guangzhou 510080, Guangdong,

People's Republic of China

Tel +86208775 5766

Email huxineikegyb@163.com
Background: Biotherapy for asthma may be useful in patients suffering from chronic obstructive pulmonary disease (COPD) with asthma characteristics. Therefore, the evaluation and close monitoring of asthma characteristics in severe and extremely severe COPD can guide treatment decisions to improve prognosis.

Methods: Stable patients suffering from COPD and having a forced expiratory volume in $1 \mathrm{~s}$ $\left(\mathrm{FEV}_{1} \%\right.$ ) of $\leq 50 \%$ (GOLD 3-4) in the First Affiliated Hospital of Sun Yat-Sen University from December 2014 to June 2018 were retrospectively enrolled in this study and evaluated in terms of their asthma characteristics (blood eosinophil counts, fractional exhaled NO [FeNO] values, and reversibility).

Results: A total of 178 patients with an average age of $65.62 \pm 9.28$ years were enrolled in this study. A total of 85 patients had an improvement of $\geq 12 \%$ in $\mathrm{FEV}_{1} \%$, and 61 of these patients had an absolute increase of $>200 \mathrm{~mL}$. Of 122 patients, 68 had blood eosinophil counts of $\geq 150$ cells $/ \mu 1$, whereas 27 showed blood eosinophil counts $\geq 300$ cells $/ \mu 1$. The blood eosinophil of $\geq 2 \%$ was found in $66 / 122(54.10 \%)$ patients, whereas $\geq 3 \%$ was found in $51 /$ $122(41.80 \%)$ patients. A total of 46 of 58 patients had an increased serum $\operatorname{IgE}$ level of $\geq 30$ $\mathrm{IU} / \mathrm{mL}$, and 32 patients had an $\mathrm{IgE}$ of $\geq 100 \mathrm{IU} / \mathrm{mL}$. The FeNO value of $\geq 25 \mathrm{ACO}$ (ppb) was found in 51/155 (32.90\%) patients. Furthermore, 43 patients had asthma-COPD overlap (ACO), and the FeNO values in the ACO group was $26.13 \pm 14.91 \mathrm{ppb}$, which was significantly higher than that in the COPD alone group $(20.99 \pm 9.16 \mathrm{ppb} ; \mathrm{P}=0.016)$. A total of 12 patients with ACO had a negative response after bronchodilation. In the COPD alone group, 34 patients had an absolute increase of $>200 \mathrm{~mL}$, whereas 55 of the 95 patients had blood eosinophil counts of $\geq 150$ cells/ $\mu$ l. The blood eosinophilia of $\geq 2 \%$ was found in $54 / 95$ (56.84\%) patients. A total of 36 of 45 patients had an increased serum IgE level of $\geq 30$ IU/ $\mathrm{mL}$. The FeNO value of $34 / 123(27.64 \%)$ patients was $\geq 25 \mathrm{ppb}$.

Conclusion: The characteristics of asthma are common findings in patients with severe and extremely severe COPD. Biomarkers should be actively used to evaluate the characteristics of asthma in these patients. If the characteristics of asthma exist, then anti-IgE or anti-IL-5 therapy should be considered to reduce exacerbation.

Keywords: chronic obstructive pulmonary disease, asthma-COPD overlap, fractional exhaled nitric oxide, blood eosinophil counts, bronchodilator reversibility

\section{Introduction}

According to 2019 GOLD guidelines, chronic obstructive pulmonary disease (COPD) is a preventable and treatable disease characterized by a persistent and progressive airflow limitation. ${ }^{1}$ COPD is a heterogeneous disease, and this characteristic has led to the development of classifications based on the following clinical phenotypes: chronic bronchitis, emphysema, and mixed pattern or asthma-COPD overlap (ACO). ${ }^{1,2}$ The 
characteristics of asthma in patients with COPD has been gaining increasing attention. These patients are associated with a poor quality of life, ${ }^{3}$ a rapid decline in pulmonary function, ${ }^{4}$ a high risk of exacerbation, ${ }^{5,6}$ and a high economic burden. ${ }^{7}$ They may benefit from targeted therapy or inhaled corticosteroid treatment compared with patients with COPD without any asthma characteristics. ${ }^{8}$

ACO is a distinct clinical phenotype that represents a subset of patients who have COPD and concomitant asthma with a prevalence ranging from $2.1 \%$ to $55 \%$ depending on different diagnostic criteria. ${ }^{9}$ ACO should be suspected in patients with COPD based on symptoms such as wheezing, paroxysmal dyspnea, and airway reversibility. In actual clinical practice, patients with COPD present with eosinophilic airway inflammation without asthma characteristics, while some patients present with asthma characteristics without meeting the ACO criteria. ${ }^{10}$ About $60 \%$ of patients with COPD may have bronchial hyperresponsiveness or reversibility without asthma. ${ }^{11}$ Patients who have ACO or COPD with asthma characteristics should be treated intensively because they predict a higher exacerbation in future. ${ }^{12}$ GINA/GOLD documents on ACO recommend that fractional exhaled NO (FeNO) and blood eosinophil counts can be used as inflammatory biomarkers in differentiating ACO from COPD. ${ }^{12}$ FeNO value does not differ significantly between patients with COPD and healthy volunteers, ${ }^{13}$ whereas FeNO value increases in a subgroup of patients who have COPD and share several common characteristics with asthma. ${ }^{14}$ Taking $25 \mathrm{ppb}$ as a cut-off value to differentiate ACO from COPD, FeNO indicated a sensitivity of $60.6 \%$ and a specificity of $87.7 \%$. ${ }^{15}$ COPD is an inflammatory disease characterized by a predominant neutrophilic inflammation. ${ }^{1}$ However, when the peripheral blood eosinophil counts of 150 cells/ $\mu \mathrm{l}$ is used as the cut-off value, the eosinophilic phenotype is found in up to $40 \%$ of patients who have COPD but have no history of asthma. ${ }^{16}$ High blood eosinophilia is one of the asthma characteristics associated with a high risk of COPD exacerbation. ${ }^{17}$ Therefore, in clinical practice, blood eosinophil counts and FeNO values can be used as biomarkers to evaluate asthmatic features in COPD patients. ${ }^{18}$

FeNO is related to interleukin (IL)-4 and IL-13mediated inflammatory pathways, while blood eosinophils are related to IL-5-mediated inflammatory pathways, respectively; target-specific inflammatory pathways are the bases of biotherapy in patients with COPD. ${ }^{19-21}$ Treatments targeting eosinophilic airway inflammation are the most promising for COPD. IL-5 is an important cytokine in the
CD4-T helper2 (Th2) pathway and implicated in the function and survival of eosinophils. ${ }^{22}$ Clinical trials have shown that mepolizumab, which is a monoclonal antibody against IL-5, can reduce the exacerbation rate of COPD by inhibiting blood eosinophilia. ${ }^{23}$ Omalizumab, which is an IgE antibody, has shown effective treatment results in patients with severe allergic asthma and COPD overlap because of the effect of binding to serum IgE. ${ }^{24}$ FeNO is the most important biomarker in anti-IgE treatment. ${ }^{19}$

Data about the characteristics of asthma in patients with COPD, especially severe and extremely severe groups, are lacking because most clinical trials on COPD exclude patients with asthma characteristics. Therefore, differentiating asthma characteristics in patients with severe and extremely severe COPD is clinically urgent because these patients are likely to have severe exacerbations that may lead to death. The close monitoring of asthma characteristics of patients with COPD can guide treatment decisions to improve prognosis.

\section{Patients and Methods}

\section{Patient Population}

Patients aged $>40$ years and suffering from severe and extremely severe COPD in the First Affiliated Hospital of Sun Yat-Sen University from December 2014 to June 2018 were retrospectively enrolled in this study in accordance with the following criteria: (1) stable patients with COPD having forced expiratory volume in $1 \mathrm{~s}\left(\mathrm{FEV}_{1} \%\right) \leq 50 \%$ (GOLD 3-4; stability was defined as no exacerbation in the least 4 weeks); (2) patients underwent bronchodilator reversibility (BDR), blood, and FeNO tests without receiving treatment of any oral or inhaled corticosteroid and bronchodilator therapy within $72 \mathrm{~h}$; and (3) nonsmokers or ex-smokers with smoking cessation for at least 6 months prior to BDR and FeNO tests. Exclusion criteria included patients with classes III and IV congestive heart failure, history of lung resection, gastroesophageal reflux disease, Parkinson's disease, dementia, and immunodeficiency diseases. In our study, ACO is defined as follows: patients with COPD, a history of asthma, and persistent partially reversible airflow limitation. ${ }^{1,9}$

The study was approved by the Institutional Research Ethics Committee of the First Affiliated Hospital of Sun Yat-sen University. Patients data were maintained with confidentiality or anonymized in accordance with the Declaration of Helsinki. The institutional review board waived the requirement for approval and signed informed 
consent form because this study was retrospective in nature and not an intervening trial.

\section{Collection procedure and data analysis}

Medical history (particularly atopy or asthma and allergy history), family history, patients' characteristics, and data (including height, weight, body surface area, smoking history, years of tobacco use, current medication information, FeNO values, blood tests, and pulmonary function test [PFT] data), were obtained from the patients' medical charts written by physicians.

\section{Measurements \\ PFT}

PFT was performed through body plethysmography in accordance with the 2014 recommendations of the Chinese National Guidelines of PFT. ${ }^{25}$ The percentage of the predicted values was calculated on the basis of healthy Chinese adults in accordance with previously determined reference values. All the subjects were required to take a PFT in a reproducible manner by a trained technician, and the best values from the acceptable tests of each subject were selected. The forced vital capacity (FVC), $\mathrm{FEV}_{1} \%$, FEV1/FVC, forced expiratory flow at $25 \%, 50 \%$, and $75 \%$ of FVC (MEF $25 \%-75 \%$ ), maximum forced peak expiratory flow, vital capacity, and diffusion capacity of the lung for CO (DLCO) were measured.

\section{BDR}

BDR test should be performed between 15 and 20 min after patients receive $400 \mu \mathrm{g}$ of inhalations of a salbutamolmetered dose inhaler with a spacer. Positive response was defined as an improvement of $\geq 12 \%$ in $\mathrm{FEV}_{1}$ and an increase in $\geq 200 \mathrm{~mL}^{25}$

\section{FeNO Measurement}

FeNO values were measured using an electrochemical analyzer (NIOX MINO Analytical Instruments, Aerocrine AB, Solna, Sweden) in accordance with the American Thoracic Society/European Respiratory Society recommendations. The participants were instructed to inhale air without NO to the total lung capacity (TLC) and immediately exhale fully into the device at a constant expiratory flow rate of $50 \mathrm{~mL} / \mathrm{s}$ for $10 \mathrm{~s}^{26}$

The cut-off points of FeNO for clinical applications as recommended by An Official ATS Clinical Practice Guideline are as follows: values more than $50 \mathrm{ppb}$ indicate a high probability of eosinophilic inflammation, values less than $25 \mathrm{ppb}$ denote a low probability of eosinophilic inflammation, and values between 25 and $50 \mathrm{ppb}$ correspond to an intermediate probability of eosinophilic inflammation. ${ }^{26}$

\section{Statistical Analysis}

Data were analyzed using SPSS version 18.0 (SPSS Inc., Chicago, IL, USA). Results were shown as median (interquartile range) for quantitative or non-normal variables when appropriate, mean \pm standard deviation (SD), or number $(\%)$ of patients. Differences between groups were assessed with Student's $t$-test for normally distributed data and Mann-Whitney $U$-test for non-normally distributed data. Categorical variables were compared via a chisquared test. The relationships between FeNO levels and $\operatorname{IgE}$ and between blood eosinophil counts and percentage were assessed by determining Spearman's rank correlation coefficients. Statistical significance was defined as $P<0.05$.

\section{Results}

\section{Study Subject Characteristics}

A total of 178 patients who were in the stable phase of COPD were enrolled in this study. The majority of the patients were males $(80 \%)$, the average age was $65.62 \pm 9.28$ years, and the mean $\mathrm{FEV}_{1} \%$ as $35.86 \% \pm 9.53 \%$. This patient group had increased (TLC) and residual volume (RV) of 104.98 $\pm 21.77 \%$ and $181.02 \% \pm 51.61 \%$, respectively. DLCO also decreased, and many patients in this group could not be examined because of their severely reduced vital capacity. The FeNO value was $22.05 \pm 10.75 \mathrm{ppb}$. The clinical characteristics and PFT data of the study population are shown in Table 1.

\section{Asthma Characteristics}

In our study, 43 patients had a history of asthma. 21 patients had atopy and allergy history, among these patients 18 cases had a definite history of asthma. 85 patients had an improvement of $\geq 12 \%$ in $\mathrm{FEV}_{1}$ after they used $400 \mu \mathrm{g}$ of inhalations of salbutamol. However, 61 of these patients had an absolute increase of $>200 \mathrm{~mL}$, and 9 patients had an increase of $>400 \mathrm{~mL}$. Among the 68 patients from 122 patients with blood eosinophil counts of $\geq 150$ cells $/ \mu 1,27$ showed blood eosinophil counts of $\geq 300$ cells $/ \mu$. The blood eosinophilia of 66 of the 122 patients $(54.10 \%)$ was $\geq 2 \%$, the blood eosinophilia of 51 of the 122 patients $(41.80 \%)$ was $\geq 3 \%$. A total of 46 of the 58 patients had an increased serum IgE level of $\geq 30$ $\mathrm{IU} / \mathrm{mL}$, whereas 32 patients had an IgE level of $\geq 100 \mathrm{IU} / \mathrm{mL}$. The FeNO value of 51 of the 155 patients (32.90\%) was $\geq 25$ ppb, and 4 of these 155 patients showed the FeNO value of $\geq 50 \mathrm{ppb}$ (Table 2). 
Table I Clinical Characteristics and PFT Data

\begin{tabular}{|l|l|}
\hline Parameter & COPD (N=I 78) \\
\hline Mean age (years) & $65.62 \pm 9.28$ \\
Sex (M:F, n) & $142: 36$ \\
Height (cm) & $164.77 \pm 7.43$ \\
Weight (kg) & $58.25 \pm 10.73$ \\
Body surface area $\left(\mathrm{m}^{2}\right)$ & $1.63 \pm 0.15$ \\
BMI in kg/m ${ }^{2}$ & $21.41 \pm 3.48$ (range: $13.84-34.67)$ \\
BMI (25-32 kg/m $\left.{ }^{2}\right)$ & $23 / 178(12.92 \%)$ \\
BMI (>32 kg/m $\left.{ }^{2}\right)$ & $4 / 178(2.25 \%)$ \\
FVC (\% predicted) & $60.96 \pm 15.83$ \\
FEVI (\% predicted) & $35.86 \pm 9.53$ \\
FEVI/FVC & $47.65 \pm 12.08$ \\
PEF (\% predicted) & $32.18 \pm 12.22$ \\
MEF (\% predicted) & $16.98 \pm 13.94$ \\
MEF25 (\% predicted) & $15.85 \pm 19.60$ \\
MEF50 (\% predicted) & $14.50 \pm 13.7 \mid$ \\
MEF75 (\% predicted) & $16.31 \pm 9.55$ \\
MVV (\% predicted) & $37.16 \pm 13.25$ \\
VC (\% predicted) & $59.34 \pm 15.26$ \\
TLC (\% predicted) & $104.98 \pm 21.77$ \\
RV (\% predicted) & $181.02 \pm 51.61$ \\
RV/TLC (\% predicted) & $67.2 \pm 10.21$ \\
DLCO (\% predicted) & $42.72 \pm 13.36$ \\
FeNO (ppb) & $22.05 \pm 10.75$ \\
\hline
\end{tabular}

Notes: Measured pulmonary function values are presented as a percentage of predictive. Data are shown as mean $\pm S D$ unless indicated otherwise.

Abbreviations: $M$, male; $F$, female; BMI, body mass index; $\mathrm{FEV}_{1}$, the forced expiratory volume in I s; FVC, forced vital capacity; PEF, peak expiratory flow; MEF, maximal mid-expiratory flow; MEF 25 , forced expiratory flow after $25 \%$ of FVC; MEF50, forced expiratory flow after $50 \%$ of FVC; MEF75, forced expiratory flow after $75 \%$ of FVC; MVV, maximal voluntary ventilation; VC, vital capacity; RV, residual volume; TLC, total lung capacity; DLCO, diffusion capacity of the lung for carbon monoxide; FeNO, fractional exhaled nitric oxide; ppb, parts per billion; COPD, chronic obstructive pulmonary disease; PFT, pulmonary function test.

According to the diagnostic criterion, 43 patients who suffered from COPD and had a history of asthma were defined ACO. The FeNO value in the ACO group was $26.13 \pm 14.91 \mathrm{ppb}$, which was significantly higher than that of the COPD alone group (20.99 $\pm 9.16 \mathrm{ppb}, P=0.016)$, but no significant differences existed in the absolute blood eosinophils and PFT values between these groups (Table 3).

In the ACO group, 12 patients had a negative response after bronchodilation and 31 patients had an improvement of $\geq 12 \%$ in $\mathrm{FEV}_{1}$. Of these 31 patients, 27 had an absolute increase of $>200 \mathrm{~mL}, 6$ had an increase of $>400 \mathrm{~mL}$. 11 of 27 patients were observed to have blood eosinophi counts of $\geq 150$ cells $/ \mu \mathrm{l}$ and 6 had $\geq 300$ cells $/ \mu$ l. Blood eosinophilia of $\geq 2 \%$ and $\geq 3 \%$ were found in $12 / 27$ (44.44\%) and $10 / 27$ $(37.03 \%)$ patients, respectively. Moreover, 10 of the 13 patients had a raised serum $\mathrm{IgE}$ level of $\geq 30 \mathrm{IU} / \mathrm{mL}$, whereas 6 patients had an $\mathrm{IgE}$ level of $\geq 100 \mathrm{IU} / \mathrm{mL}$. The FeNO value
Table 2 Asthma Characteristics in Patients with Severe and Extremely Severe COPD

\begin{tabular}{|c|c|}
\hline Parameter & \\
\hline History of asthma & $43 / 178(24.15 \%)$ \\
\hline History of atopy and allergy & $21 / 178(11.80 \%)$ \\
\hline Total serum lgE (IU/mL) & Median I28.85 (I.7-817.7) \\
\hline $\lg \mathrm{E} \geq 30(\mathrm{IU} / \mathrm{mL})$ & $46 / 58(79.31 \%)$ \\
\hline $\lg E \geq 100(\mathrm{IU} / \mathrm{mL})$ & $32 / 58(55.17 \%)$ \\
\hline Blood eosinophil absolute (cells/ $\mu$ l) & $232.05 \pm 217.39(0-1000)$ \\
\hline Blood eosinophils $\geq I 50$ cells $/ \mu \mid$ & $68 / / 22(55.74 \%)$ \\
\hline Blood eosinophils $\geq 300$ cells $/ \mu \mathrm{l}$ & $27 / 122(22.13 \%)$ \\
\hline Blood eosinophils $\geq 2 \%$ & $66 / 122(54.10 \%)$ \\
\hline Blood eosinophils $\geq 3 \%$ & $5 \mathrm{I} / 122(4 \mid .80 \%)$ \\
\hline \multicolumn{2}{|l|}{ Bronchodilator response (BDR) } \\
\hline$\geq 12 \%$ increase in $\mathrm{FEV}$, & $85 / 178(47.75 \%)$ \\
\hline$\geq 12 \%+\geq 200 \mathrm{~mL}$ in FEV & $61 / 178(34.27 \%)$ \\
\hline$\geq 12 \%+\geq 400 \mathrm{~mL}$ in $\mathrm{FEV}_{1}$ & $9 / 178(5.06 \%)$ \\
\hline FeNO (ppb) & $22.05 \pm 10.75$ \\
\hline FeNO $(\mathrm{ppb}) \geq 25$ & $51 / 155(32.90 \%)$ \\
\hline $\mathrm{FeNO}(\mathrm{ppb}) \geq 50$ & $4 / 155(2.58 \%)$ \\
\hline
\end{tabular}

Note: Data are shown as mean \pm SD unless indicated otherwise.

of $\geq 25 \mathrm{ppb}$ was found in $17 / 32$ (53.12\%) patients, and only 3 of these patients showed FeNO values of $\geq 50 \mathrm{ppb}$ (Table 3).

In the COPD group, 54 patients had an improvement of $\geq 12 \%$ in $\mathrm{FEV}_{1}$. Of these patients, 34 had an absolute increase of $>200 \mathrm{~mL}$ and $3 \mathrm{had}$ an increase of $>400 \mathrm{~mL}$. A total of 55 of 95 patients had blood eosinophil counts of $\geq 150$ cells $/ \mu$ l, whereas 21 patients had blood eosinophil counts of $\geq 300$ cells $/ \mu 1$. Furthermore, 54/95 (56.84\%) and $41 / 95$ (43.16\%) patients had blood eosinophilia of $\geq 2 \%$ and $\geq 3 \%$, respectively. In addition, 36 of the 45 patients had an increased serum IgE level of $\geq 30 \mathrm{IU} / \mathrm{mL}$, whereas 26 patients had $\geq 100 \mathrm{IU} / \mathrm{mL}$. Moreover, 34/123 (27.64\%) had a FeNO value of $\geq 25 \mathrm{ppb}$, and only 1 of these patients showed FeNO value of $\geq 50 \mathrm{ppb}$ (Table 3).

According to the severity of airway obstruction, the patients were divided into severe $\left(30 \% \leq \mathrm{FEV}_{1}<50 \%\right)$ and extremely severe $\left(\mathrm{FEV}_{1}<30 \%\right)$ cases with COPD. The differences in FeNO values, bronchodilator reversibility, serum IgE, and blood eosinophil counts with regard to the severity of airway obstruction were not significant (Table 4).

The correlations between FeNO values and blood eosinophil counts in patients with severe and extremely severe COPD were not significant (Figure 1).

In this retrospective study, nine patients were reviewed for PFT and FeNO measurements 3 months after treatment (ICS 
Table 3 Asthma Characteristics in Patients with Asthma-COPD Overlap (ACO) and COPD Alone

\begin{tabular}{|c|c|c|c|}
\hline Parameter & $\operatorname{Acos}(\mathrm{N}=43)$ & COPD Alone $(\mathrm{N}=135)$ & p-Value \\
\hline Mean age (years) & $61.63 \pm 9.91$ & $66.90 \pm 8.73$ & 0.208 \\
\hline $\operatorname{Sex}(M: F, n)$ & $30: 13$ & $112: 23$ & 0.061 \\
\hline Height (cm) & $164.42 \pm 7.73$ & $164.88 \pm 7.36$ & 0.723 \\
\hline Weight (kg) & $60.27 \pm 10.34$ & $57.60 \pm 10.81$ & 0.155 \\
\hline Body surface area $\left(\mathrm{m}^{2}\right)$ & $1.65 \pm 0.16$ & $1.62 \pm 0.16$ & 0.257 \\
\hline BMI $\left(\mathrm{kg} / \mathrm{m}^{2}\right)$ & $22.22 \pm 3.07$ & $21.15 \pm 3.57$ & 0.082 \\
\hline FVC (\% predicted) & $63.09 \pm 13.33$ & $60.27 \pm 16.53$ & 0.311 \\
\hline FEV (\% predicted) & $36.88 \pm 9.62$ & $35.53 \pm 9.51$ & 0.420 \\
\hline $\mathrm{FEV}_{\mathrm{I}} / \mathrm{FVC}$ & $47.21 \pm 10.21$ & $47.79 \pm 12.64$ & 0.786 \\
\hline PEF (\% predicted) & $33.88 \pm 12.26$ & $31.64 \pm 12.20$ & 0.295 \\
\hline MEF (\% predicted) & $16.02 \pm 7.10$ & $|7.29 \pm| 5.5 \mid$ & 0.606 \\
\hline MEF25 (\% predicted) & $|4.2| \pm \mid 4.39$ & $16.38 \pm 21.01$ & 0.529 \\
\hline MEF50 (\% predicted) & $13.16 \pm 6.66$ & $14.93 \pm 15.29$ & 0.464 \\
\hline MEF75 (\% predicted) & $15.30 \pm 7.44$ & $16.63 \pm 10.14$ & 0.429 \\
\hline MVV (\% predicted) & $36.47 \pm \mid 1.91$ & $37.38 \pm 13.68$ & 0.695 \\
\hline VC (\% predicted) & $61.91 \pm 13.97$ & $58.53 \pm 15.62$ & 0.207 \\
\hline TLC (\% predicted) & $100.39 \pm 14.69$ & $106.13 \pm 23.13$ & 0.260 \\
\hline RV (\% predicted) & $|72.57 \pm 38.6|$ & $183.13 \pm 54.35$ & 0.382 \\
\hline RV/TLC (\% predicted) & $63.52 \pm 8.27$ & $68.12 \pm 10.47$ & 0.053 \\
\hline DLCO (\% predicted) & $46.58 \pm 13.39$ & $41.50 \pm 13.30$ & 0.255 \\
\hline Total serum IgE (IU/mL) & $|5| .17 \pm 43.45$ & $199.16 \pm 30.79$ & 0.442 \\
\hline $\lg \mathrm{E} \geq 30 \mathrm{IU} / \mathrm{mL}$ & $10 / 13$ & $36 / 45$ & 0.809 \\
\hline $\lg \mathrm{E} \geq 100 \mathrm{IU} / \mathrm{mL}$ & $6 / 13$ & $26 / 45$ & 0.066 \\
\hline Blood eosinophil absolute (cells/ $\mu$ l) & $230.37 \pm 215.24$ & $232.53 \pm 206.91$ & 0.961 \\
\hline Blood eosinophils $\geq 150$ (cells/ $\mu \mathrm{l})$ & $11 / 27$ & $55 / 95$ & 0.114 \\
\hline Blood eosinophils $\geq 300$ (cells/ $\mu$ l) & $6 / 27$ & $21 / 95$ & 0.990 \\
\hline Blood eosinophils (\%) & $2.69 \pm 2.49$ & $3.13 \pm 2.78$ & 0.452 \\
\hline Blood eosinophils $\geq 2 \%$ & $12 / 27$ & $54 / 95$ & 0.254 \\
\hline Blood eosinophils $\geq 3 \%$ & $10 / 27$ & $41 / 95$ & 0.569 \\
\hline \multicolumn{4}{|l|}{ Bronchodilator response (BDR) } \\
\hline$\geq 12 \%$ increase in $\mathrm{FEV}_{\mathrm{I}}$ & $31 / 43$ & $54 / 135$ & $<0.001$ \\
\hline$\geq 12 \%+\geq 200 \mathrm{~mL}$ in $\mathrm{FEV}_{\mathrm{I}}$ & $27 / 43$ & $34 / 135$ & $<0.001$ \\
\hline$\geq 12 \%+\geq 400 \mathrm{~mL}$ in $\mathrm{FEV}$, & $6 / 43$ & $3 / 135$ & 0.007 \\
\hline $\mathrm{FeNO}(\mathrm{ppb})$ & $26.13 \pm|4.9|$ & $20.99 \pm 9.16$ & 0.016 \\
\hline $\mathrm{FeNO}(\mathrm{ppb}) \geq 25$ & $17 / 32$ & $34 / 123$ & 0.016 \\
\hline $\mathrm{FeNO}(\mathrm{ppb}) \geq 50$ & $3 / 32$ & $1 / 123$ & 0.028 \\
\hline
\end{tabular}

Notes: Measured pulmonary function values are presented as the percentage of predictive. Data are shown as mean \pm SD unless indicated otherwise.

Abbreviations: M, male; F, female; BMI, body mass index; $\mathrm{FEV}_{1}$, the forced expiratory volume in I s; FVC, forced vital capacity; PEF, peak expiratory flow; MEF, maximal mid-expiratory flow; MEF25, forced expiratory flow after 25\% of FVC; MEF50, forced expiratory flow after 50\% of FVC; MEF75, forced expiratory flow after 75\% of FVC; MVV, maximal voluntary ventilation; VC, vital capacity; RV, residual volume; TLC, total lung capacity; DLCO, diffusion capacity of the lung for carbon monoxide; FeNO, fractional exhaled nitric oxide; Ppb, parts per billion; COPD, chronic obstructive pulmonary disease; and ACOS, asthma-COPD overlap syndrome.

$+\mathrm{LABA}+\mathrm{LAMA})$. Most patients showed an improved lung function and a decreased FeNO, but the differences were statistically not significant. Figure 2 presents the FeNO values and $\mathrm{FEV}_{1}$ before and after treatment during follow-up.

\section{Discussion}

We performed a retrospective study to observe the asthmatic characteristics in stable patients with COPD and having
$\mathrm{FEV}_{1} \% \leq 50 \%$ (GOLD 3-4). TLC, RV and RV/TLC significantly increased, and DLCO decreased significantly. The patients in this category were at a high risk of acute exacerbations, had complex conditions and history, and required detailed evaluation and treatment even during the stable phase.

The main findings of our study included the following: FeNO was important for phenotype assessment with 
Table 4 Asthma Characteristics in Patients with Severe and Extremely Severe COPD

\begin{tabular}{|c|c|c|c|}
\hline Parameter & $30 \% \leq$ FEV $_{1} \leq \mathbf{5 0} \%(126)$ & FEV $_{1}<30 \%(52)$ & p-Value \\
\hline History of asthma & $33 / 126$ & $10 / 52$ & 0.324 \\
\hline Total serum IgE (IU/mL) & Median $103.8(<1.7-8 \mid 7.7)$ & Median I60.9 (8.2I-758.9) & 0.299 \\
\hline $\lg \mathrm{E} \geq 30 \mathrm{IU} / \mathrm{mL}$ & $33 / 43$ & $13 / 15$ & 0.490 \\
\hline $\lg \mathrm{E} \geq 100 \mathrm{IU} / \mathrm{mL}$ & $22 / 43$ & $10 / 15$ & 0.374 \\
\hline Blood eosinophil absolute (cells/ul) & $240.78 \pm 215.39$ & $207.50 \pm 224.54$ & 0.964 \\
\hline Blood eosinophils $\geq 150$ cells $/ \mu \mathrm{l}$ & $54 / 90$ & $14 / 32$ & 0.112 \\
\hline Blood eosinophils $\geq 300$ cells $/ \mu \mathrm{l}$ & $23 / 90$ & $4 / 32$ & 0.145 \\
\hline Percent & $3.16 \pm 2.69$ & $2.68 \pm 2.65$ & 0.452 \\
\hline Blood eosinophils $\geq 2 \%$ & $50 / 90$ & $16 / 32$ & 0.588 \\
\hline Blood eosinophils $\geq 3 \%$ & $42 / 90$ & $9 / 32$ & 0.068 \\
\hline \multicolumn{4}{|l|}{ Bronchodilator response (BDR) } \\
\hline$\geq 12 \%$ increase in $\mathrm{FEV}_{1}$ & $62 / 126$ & $23 / 52$ & 0.546 \\
\hline$\geq 12 \%+\geq 200 \mathrm{~mL}$ in $\mathrm{FEV}_{1}$ & $47 / 126$ & $14 / 52$ & 0.185 \\
\hline$\geq 12 \%+\geq 400 \mathrm{~mL}$ in $\mathrm{FEV}$, & $8 / 126$ & $1 / 52$ & 0.287 \\
\hline \multicolumn{4}{|l|}{ FeNO (ppb) } \\
\hline $\mathrm{FeNO}(\mathrm{ppb}) \geq 25$ & $39 / 108$ & $12 / 47$ & 0.237 \\
\hline $\mathrm{FeNO}(\mathrm{ppb}) \geq 50$ & $3 / 108$ & $1 / 47$ & 1.000 \\
\hline
\end{tabular}

Note: Data are shown as mean \pm SD unless indicated otherwise.

Abbreviations: FeNO, fractional exhaled nitric oxide; and ppb, parts per billion.

significantly higher levels detected in the ACO phenotype than in COPD alone group. In COPD, CD8+ lymphocytes, macrophages, and neutrophils are predominant. ${ }^{27}$ Therefore, the FeNO values and blood eosinophil counts did not increase in our cohort. Several patients with a mixed phenotype could present the characteristics of asthma with predominant eosinophils and TH2 lymphocytes, which could be measured indirectly with FeNO produced by epithelial cells in response to ILs, such as IL-4 and IL-13. ${ }^{20,21}$ Few studies have assessed the FeNO value in patients suffering from COPD and having severe and extremely severe airflow obstruction. Patients with ACO have higher rates of exacerbation and poorer quality of life than those with COPD alone. ${ }^{5,6}$ In patients with severe COPD, a large proportion had frequent exacerbations despite the intensive inhaled bronchodilator therapy, systemic corticosteroids, or additional treatments. Therefore, patients with severe and extremely severe COPD combined with asthma must be closely monitored and treated. Our study confirmed the potential role of FeNO as a biomarker in identifying asthma in groups with severe and extremely severe COPD. The PFT values did not significantly differ between the COPD alone and ACO groups $(P>0.05)$.

We divided the patients into two groups: ACO and COPD alone. Of the 43 patients with ACO, 27 (62.79\%) had truepositive BDR reversibility (improvement of $\geq 12 \%$ in $\mathrm{FEV}_{1} \%$ and an increase of $>200 \mathrm{~mL}$ ). Some patients with ACO had severe airflow limitation as $\mathrm{FEV}_{1} \%$ increased by $12 \%$, but the absolute value hardly exceeded $200 \mathrm{~mL}$. In 12 patients with long-term asthma, airflow was completely irreversible. We conclude that patients with ACO after long-term treatment with dual or triple inhalation, the degree of airway reversibility is reduced. ${ }^{28}$ Previous study has suggested that approximately $60 \%$ of patients with COPD could have airway hyperresponsiveness or reversibility without asthma. ${ }^{11}$ For the COPD alone group, 34 patients had significant bronchodilator reversibility, with an improvement of $\geq 12 \%$ in $\mathrm{FEV}_{1} \%$ and an increase of $>200 \mathrm{~mL}$ without asthma history. These values were lower than those reported by Sandhya Matthes ${ }^{18}$ because we enrolled patients with extremely severe obstruction and achieved $200 \mathrm{~mL}$ of BDR. Hence, reversibility is a distinguishing characteristic between asthma and COPD to some extent, but it is not the most important factor in distinguishing $\mathrm{ACO}$ in patients with severe and extremely severe COPD.

Eosinophils can play a critical role in $10-40 \%$ of patients with COPD. ${ }^{29}$ Other markers, such as eosinophils in peripheral blood, may be significant and easily determined. Eosinophils are cells that generally exist in small percentages in the peripheral blood and have considerable variability. ${ }^{27,30}$ In our study, blood eosinophil counts were acquired from 122 of the 178 enrolled patients. A total of 

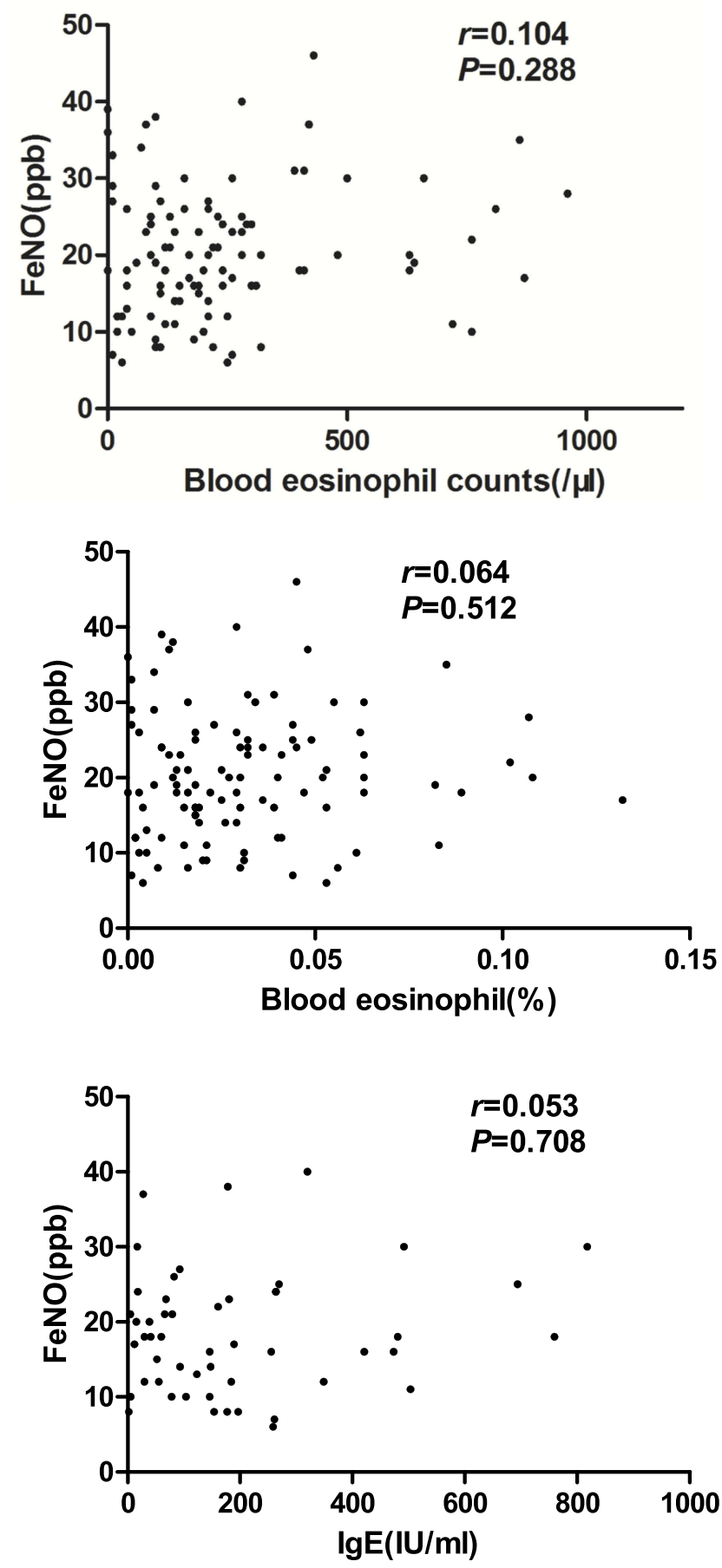

Figure I Correlation of FeNO values with blood eosinophil counts and blood eosinophil percentage in patients with severe and extremely severe COPD.

Notes: The correlations between FeNO values and blood eosinophil counts were determined by calculating Spearman's rank correlation coefficients.

Abbreviation: FeNO, fractional exhaled nitric oxide.

$54.10 \%$ of the patients had levels higher than $2 \%$, and $55.74 \%$ patients had blood eosinophil counting of $\geq 150$ cells $/ \mu 1$, which was higher than those reported in other studies. Of the 58 patients, 32 had an increased serum $\mathrm{IgE}$ level of $\geq 100 \mathrm{IU} / \mathrm{mL}$. 51 of the 155 patients
(32.90\%) the FeNO value was $\geq 25$ ppb. Approximately $54.1 \%$ of patients with COPD showed blood eosinophilia of $\geq 2 \%$, thereby suggesting that this criterion was unsuitable to be used alone in differentiating the asthma phenotype with any clinical relevance. Many patients with COPD might present with eosinophilic airway inflammation without asthma.

A study has shown that $\mathrm{FeNO}$ is not better than blood eosinophil counts in patients with COPD. ${ }^{31}$ Considering that FeNO and blood eosinophil counts show similar diagnoses in determining ACO phenotypes, Ramírez et al thought that blood eosinophil counts are enough, and FeNO does not need to be measured. However, the results of our study did not agree with this conclusion. First, they enrolled patients with AECOPD, but we enrolled stable patients with GOLD 3-4. Second, the differences in airway inflammation were based on different cell profiles. In our study, the correlations between FeNO values and blood eosinophil counts in patients with severe and extremely severe COPD were not significant. FeNO and blood eosinophil counts should be both evaluated in patients with COPD.

In this retrospective study, nine patients were reviewed for PFT and FeNO measurements 3 months after the treatment. Although lung function and FeNO improved, the differences between these variables were not significant. Therefore, larger sample size and more observations are needed to confirm the results.

This work is a retrospective study; hence, it has several limitations. First, many patients were under treatment with dual- or triple-inhaled treatments (bronchodilator therapy and corticosteroids). Although patients stopped these treatments within $72 \mathrm{~h}$ before they underwent a blood test, a PFT, and a FeNO test, data might have been partially affected. ${ }^{32}$ Second, induced sputum could directly reflect the characteristics of airway inflammation, but the technical requirements of sputum processing and cell counting might limit its feasibility in routine clinical practice. The correlation between sputum and blood eosinophil is moderate, blood test is easily conducted, and cell counting is standardized in laboratories. ${ }^{27,29,30}$ Therefore, in this study, blood eosinophilia was used instead of sputum eosinophilia. Third, we standardized the FeNO test and PFT and excluded patients with other diseases that might affect FeNO values. For example, we excluded current smokers, but we were unsure how the coexistence of other diseases affected our study. Lastly, different diagnostic criteria slightly influenced the definition of ACO 

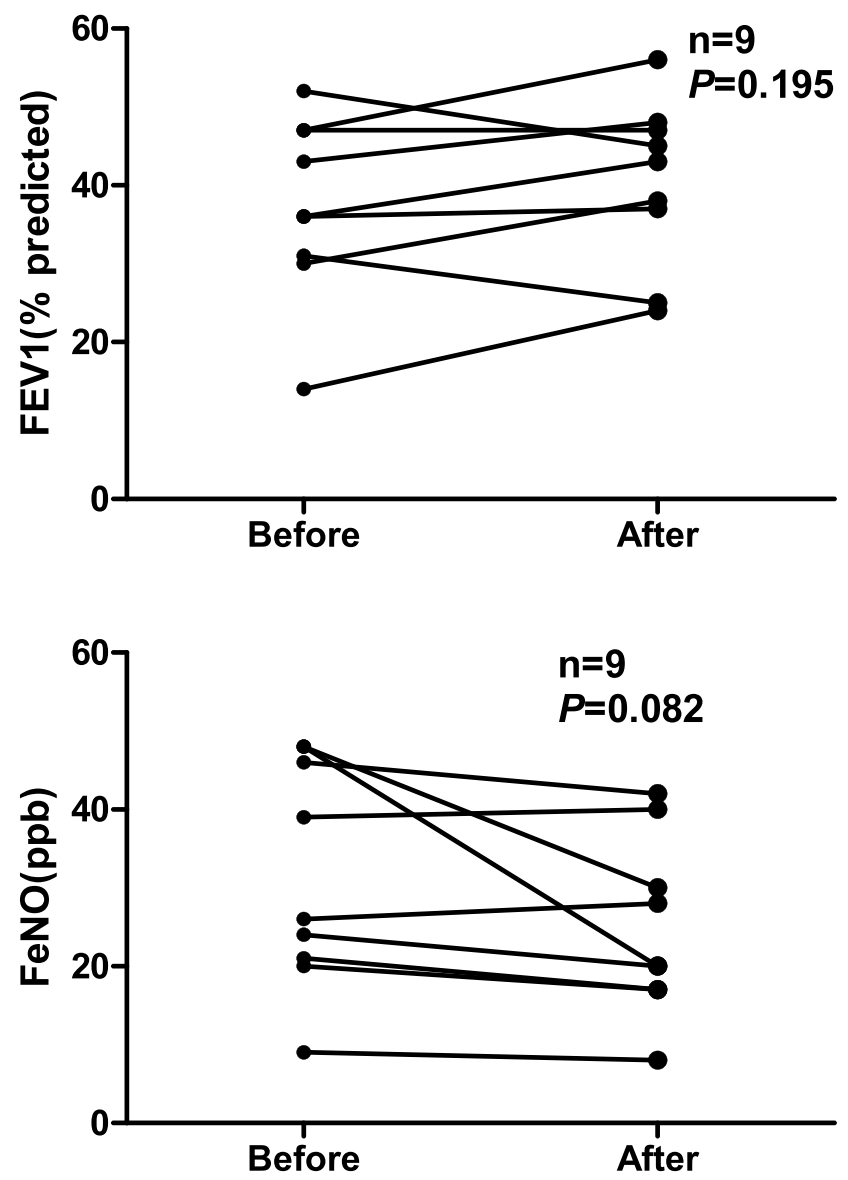

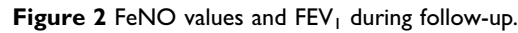
Abbreviation: FeNO, fractional exhaled NO.

population, and the definition of patients with a history of asthma in our study was reasonable.

In this study, a certain number of patients with severe and extremely severe COPD can have asthma or present with asthma characteristics (high blood eosinophil counts, high FeNO values, and reversibility). Asthma and its characteristics in patients with COPD represent a treatable trait due to targeted therapy. This study carefully analyzed patients with severe and extremely severe COPD and highlighted a subgroup of patients who had asthma characteristics and were more likely to suffer from severe exacerbation. This aspect should be close monitored in clinical practice.

\section{Conclusion}

Asthma characteristics, such as airway reversibility, high FeNO values, and blood eosinophil counts, are common findings in patients with severe and extremely severe COPD, but clinically relevant values need to be further determined. Biomarkers should be actively used to evaluate the asthma characteristics in these patients. If the characteristics of asthma exist, then anti-IgE or anti-IL-5 therapy should be considered for these patients to reduce exacerbation.

\section{Disclosure}

The authors report no conflicts of interest in this work.

\section{References}

1. Global Initiative for Chronic Obstructive Lung Disease. Report global strategy for the diagnosis, management, and prevention of chronic obstructive pulmonary disease 2019 report. Available from: www. goldcopd.org.

2. Miravitlles M, Soler-Cataluna JJ, Calle M, et al. Spanish Guidelines for Management of Chronic Obstructive Pulmonary Disease (GesEPOC) 2017. Pharmacological treatment of stable phase. Arch Bronconeumol. 2012;48:247-257. doi:10.1016/j.arbres.2012.04.001

3. Kauppi P, Kupiainen H, Lindqvist A, et al. Overlap syndrome of asthma and COPD predicts low quality of life. J Asthma. 2011;48:279-285. doi:10.3109/02770903.2011.555576

4. McDonald VM, Simpson JL, Higgins I, Gibson PG. Multidimensional assessment of older people with asthma and COPD: clinical management and health status. Age Ageing. 2011;40:42-49. doi:10.1093/ageing/afq134

5. Bateman ED, Reddel HK, van Zyl-smit RN, Agusti A. The asthma-COPD overlap syndrome: towards a revised taxonomy of chronic airways diseases? Lancet Respir Med. 2015;3:719-728. doi:10.1016/S2213-2600(15)00254-4

6. Nielsen M, Barnes CB, Ulrik CS. Clinical characteristics of the asthma-COPD overlap syndrome-a systematic review. Int $J$ Chron Obstruct Pulmon Dis. 2015;10:1443-1454. doi:10.2147/COPD. S85363

7. Shaya FT, Dongyi D, Akazawa MO, et al. Burden of concomitant asthma and COPD in a Medicaid population. Chest. 2008;134:14-19. doi:10.1378/chest.07-2317

8. Bafadhel M, McKenna S, Terry S, et al. Blood eosinophils to direct corticosteroid treatment of exacerbations of chronic obstructive pulmonary disease: a randomized placebo-controlled trial. Am J Respir Crit Care Med. 2012;186:48-55. doi:10.1164/rccm.201108-1553OC

9. Corlateanu A, Covantev S, Mathioudakis A, Botnaru V, Siafakas N. Asthma-chronic obstructive pulmonary disease overlap syndrome (ACOS): current evidence and future research directions. COPD Res Prac. 2017;3:6. doi:10.1186/s40749-017-0025-x

10. Leigh R, Pizzichini MM, Morris MM, Maltais F, Hargreave FE, Pizzichini E. Stable COPD: predicting benefit from high-dose inhaled corticosteroid treatment. Eur Respir J. 2006;27:964-981. doi:10.1183/09031936.06.00072105

11. Barrecheguren M, Román-Rodríguez M, Miravitlles M. Is a previous diagnosis of asthma a reliable criterion for asthma-COPD overlap syndrome in a patient with COPD? Int J Chronic Obstructive Pulm Dis. 2015;10:1745-1752.

12. Global Initiative for Asthma, Global Initiative for Chronic Obstructive Lung Disease. Diagnosis of disease of chronic airflow limitation: asthma, COPD, and Asthma-COPD Overlap Syndrome (ACOS). Available from: http://www.ginasthma.org/local/uploads/ files/ACOS_2015.pdf. Accessed February 20, 2018.

13. Donohue JF, Herje N, Crater G, Rickard K. Characterization of airway inflammation in patients with COPD using fractional exhaled nitric oxide levels: a pilot study. Int J Chronic Obstructive Pulm Dis. 2014;9:745-751. doi:10.2147/COPD

14. Tamada T, Sugiura H, Takahashi T, et al. Biomarker-based detection of asthma-COPD overlap syndrome in COPD populations. Int $J$ Chronic Obstructive Pulm Dis. 2015;10:2169-2176. doi:10.2147/COPD.S88274 
15. Takayama Y, Ohnishi H, Ogasawara F, et al. Clinical utility of fractional exhaled nitric oxide and blood eosinophils counts in the diagnosis of asthma-COPD overlap. Int J Chronic Obstructive Pulm Dis. 2018;13:2525-2532. doi:10.2147/COPD

16. McDonald CF. Eosinophil Biology in COPD. $N$ Engl J Med. 2017;377:1680-1682. doi:10.1056/NEJMe1710326

17. Vedel-Krogh S, Nielsen SF, Lange P, Vestbo J, Nordestgaard BG. Blood eosinophils and exacerbations in chronic obstructive pulmonary disease - the copenhagen general population study. Am J Respir Crit Care Med. 2016;193:965-974. doi:10.1164/rccm.201509$18690 \mathrm{C}$

18. Matthes S, Stadler J, Barton J, et al. Asthma features in severe COPD: identifying treatable traits. Respir Med. 2018;145:89-94. doi:10.1016/j.rmed.2018.10.027

19. Pavord ID. Biologics and chronic obstructive pulmonary disease. $J$ Allergy Clin Immunol. 2018;141:1983-1991. doi:10.1016/j. jaci.2018.04.020

20. Alving K, Malinovschi A. Basic aspects of exhaled nitric oxide. Eur Respir Soc Monogr. 2010;49:1-31.

21. Stirling RG, van Rensen EL, Barnes PJ, Chung KF. Interleukin-5 induces CD34(+) eosinophil progenitor mobilization and eosinophil CCR3 expression in asthma. Am J Respir Crit Care Med. 2001;164:1403-1409. doi:10.1164/ajrccm.164.8.2010002

22. Bafadhel M, Pavord ID, Russell REK. Eosinophils in COPD: just another biomarker? Lancet Respir Med. 2017;5:747-759. doi:10.1016/S2213-2600(17)30217-5

23. Pavord ID, Chanez P, Criner GJ, Kerstjens HAM, Korn S. Mepolizumab for eosinophilic chronic obstructive pulmonary disease. $N$ Engl J Med. 2017;377:1613-1629. doi:10.1056/NEJMoa1708208

24. Maltby S, Gibson PG, Powell H, McDonald VM. Omalizumab treatment response in a population with severe allergic asthma and overlapping. COPD Chest. 2017;151:78-89. doi:10.1016/j.chest.2016.09.035
25. Chinese Thoracic Society. The Chinese national guidelines of pulmonary function test.Chin J Tuberc Respir Dis. 2014;37:566-571. Available from http://zhjhhhxzz.yiigle.com/CN112147201408/860037.htm. Accessed November 11, 2019.

26. American Thoracic Society,European Respiratory Society. ATS/ERS recommendations for standardized procedures for the online and offline measurement of exhaled lower respiratory nitric oxide and nasal nitric oxide, 2005. Am J Respir Crit Care Med. 2005;171:912-930. doi:10.1164/rccm.200406-710ST

27. Couillard S, Larivée P, Courteau J, Vanasse A. Eosinophils in COPD exacerbations are associated with increased readmissions. Chest. 2017;151:366-373. doi:10.1016/j.chest.2016.10.003

28. Sin DD. Asthma-copd overlap syndrome: what we know and what we don't. Tuberc Respir Dis. 2017;80:11-20. doi:10.4046/trd.2017.80.1.11

29. George L, Brightling CE. Eosinophilic airway inflammation: role in asthma and chronic obstructive pulmonary disease. Ther Adv Chronic Dis. 2016;7:34-51. doi:10.1177/2040622315609251

30. Carr TF, Zeki AA, Kraft M. Eosinophilic and Noneosinophilic Asthma. Am J Respir Crit Care Med. 2018;197:22-37. doi:10.1164/ rccm.201611-2232PP

31. Río Ramírez MT, Juretschke Moragues MA, Fernández González R, et al. Value of exhaled nitric oxide (FeNO) and eosinophilia during the exacerbations of chronic obstructive pulmonary disease requiring hospital admission. Int $J$ Chronic Obstructive Pulm Dis. 2018;15:369-376. doi:10.1080/15412555.2018.1482532

32. Kharitonov SA, Yates DH, Barnes PJ. Inhaled glucocorticoids decrease nitric oxide in exhaled air of asthmatic patients. Am J Respir Crit Care Med. 1996;153:454 457. doi:10.1164/ajrccm.153.1.8542158

\section{Publish your work in this journal}

The International Journal of COPD is an international, peer-reviewed journal of therapeutics and pharmacology focusing on concise rapid reporting of clinical studies and reviews in COPD. Special focus is given to the pathophysiological processes underlying the disease, intervention programs, patient focused education, and self management protocols. This journal is indexed on PubMed Central, MedLine and CAS. The manuscript management system is completely online and includes a very quick and fair peer-review system, which is all easy to use. Visit http://www.dovepress.com/testimonials.php to read real quotes from published authors. 